\title{
LA MÁQUINA DE VISIÓN: ESTUDIOS DE GÉNERO E
}

\section{IMAGENES}

\section{VISION MACHINE: GENDER STUDIES AND IMAGES}

Amalia Ortiz De Zárate Víctor Silva

Universidad de Playa Ancha, Valparaíso, Chile

1 aortizdezarate@uach.cl, vsilva@upa.c

RESUMEN:

En el cine se potencian las relaciones Arbitrary and symbolic relationships which arbitrarias y simbólicas que han sido have been set up culturally regarding woman establecidas culturalmente con relación a la are boosted in the cinema. These relationships mujer. Dichas relaciones situan a la mujer, al consider woman, at the same time, as an objec mismo tiempo, como objeto y fundamento de and foundation of the representation, end la representación, fin y origen del deseo del and origin of man desire and of the impulse hombre y de su impulso de representarlo, $y$ of representing him, and object and sign of objeto y signo de $(\mathrm{su})$ cultura y creatividad her culture and creativity. At the same time, A su vez éste funciona como máquina de works as an ima A su vez, étén fun creación de imágenes, que al producir dichas also tends to produce woman as icon when magenes (de mujeres o no) tiende también a images (of women or not) are produced. And reproducir a la mujer como icono. Y en este it is defined in relation to a masculine subject proceso de subjetivación se define en relación in the subjectivation process; with man as a un sujeto masculino; con el hombre como only point of reference único término de referencia.

Palabras claves:

KEY WORD:

Cinema, woman, subjectivation, image-time, Cine, mujer, subjetivación, imagen-tiempo, image-movement.

imagen-movimiento.
En el cine lo central es la mirada, tanto mental como física. El ojo está ya en las cosas, forma parte de la imagen, es su visibilidad. El ojo no es sólo la cámara sino también -y básicamente- la pantalla.

A nivel receptivo los cambios son radicales. A diferencia de la contemplación estética del cuadro, el cinematógrafo tiende a disminuir la diferencia entre el observador y la obra. Con ello aumenta la separación entre los espectadores y la realidad exterior. Deesta forma nos encontramos con la producción de una "nueva realidad" o de una segunda naturaleza. El papel activo "espectatorial" que deslegitima cualquier pasividad de espectador se convierte en un elemento clave para la posterior conformación de una teoría feminista sobre el cine.

No hay que olvidar que el discurso pre-feminista sobre el cine no tenía en cuenta la producción "cinemática" de las posiciones espectatoriales sobre la diferencia sexual (de Lauretis, 1992)

Por otro lado, el cine -a diferencia de otras artes- no guarda una relación exterior con el movimiento, sino que crea el automovimiento de la imagen. Esto es, el cine como arte industrial alcanza el automovimiento, el movimiento automático, hace del movimiento el dato inmediato de la imagen (Deleuze). Por tanto, el movimiento ya no depende de un móvil o un objeto que lo ejecute, ni de una mente que lo reconstruya, sino que la propia imagen, en sí misma, se mueve. En este caso, la imagen no es figurativa, ni abstracta.

Si se compara con otras artes, se tendrá en cuenta esa especificidad del cine. Porque las imágenes pictóricas son inmóviles; la mente es la que hace el movimiento. En el caso de las literarias, la producción del movimiento se da en la virtualidad mental del lector. Las imágenes coreográficas o dramáticas permanecen adheridas a un móvil. Sin embargo, en el caso de las imágenes cinematográficas, el movimiento es automático. La imagen cinematográfica hace ella misma el movimiento, efectúa lo que las otras artes se limitan a exigir (o a decir), recoge lo esencial de esas artes, hereda de ellas. En síntesis, es como el modo de empleo de otras imágenes, convirtiendo en potencia lo que era posibilidad.

Lo mismo ocurre con la temporalidad... Cuando se pasa de las imágenes-movimiento a las imágenes-tiempo, la temporalidad es automática, se produce la autotemporalidad. No cesa el movimiento, sino que las relaciones entre tiempo y movimiento se invierten. El tiempo ya no deriva del montaje (es decir, de la composición de las imágenesmovimiento), sino que el proceso se revierte y el movimiento deriva del tiempo. No desaparece el montaje de forma necesaria, pero cambia de sentido, se muta, como dice Lapoujade, en "exhibición” (en Deleuze, 1996: 87). 
El cine relaciona elementos técnicos, subjetivos y sociales. El montaje de los tres identifica y produce subjetivaciones ${ }^{1}$ pero no agota al sujeto. Por ello, interpela a hombres y mujeres pero de manera diferente. En el segundo caso, instala a la mujer en un particular orden social y natural (arbitrario cultural, diría Bourdieu). El cuerpo desnudo de la mujer se convierte en la imagen de la verdad. Un excelente ejemplo de este movimiento hacia la verdad puede observarse en la película afgana Osama, de Siddiq Barmak². En el momento en que la niña (Osama) debe desnudarse para tomar el baño purificador con sus demás compañeros en la escuela religiosa (talibán) a la que asiste de incógnito y, con el objeto de ocultar su sexo, decide darse aquel baño envuelta en una tela. Se cubre con el "velo" para ocultar su cuerpo desnudo: oculta la imagen de la verdad.

Si se pretende analizar el discurso de género sobre el cine con la intención de construir una cultura basada en la pluralidad y la multiplicidad, hay que partir de la idea de que los estudios de género rechazan las relaciones sociales existentes y las definiciones y valores culturales dados de antemano. Por ello, es fundamental tener en cuenta los cambios en el cine y en su distribución sígnica, ya que implica que no existe ningún valor eterno vinculado a éstas artes sino que su fundamento está en el cambio y en la trasgresión. Las imágenes cambian tanto como posibilidades de clasificación existan.

Por otro lado, con el cine surge el espectáculo como mecanismo de explotación del sistema capitalista, que se radicaliza en el capitalismo tardío con el incremento de las instancias culturales de dominación económica y estética. El lugar que ocupa la mujer es el del cuerpo para ser mirado, el lugar de la sexualidad y el objeto del deseo (de Lauretis, 1992).

1 Conviene desarrollar una breve aproximación al término subjetivación. Maurice Florence (pseudónimo de M. Foucault), en el Dictionnaire de philosophes, indica que la subjetivación trata "en suma, de la historia de la 'subjetividad', si entendemos esta palabra como el modo en que el sujeto hace la experiencia de sí mismo en un juego de verdad en el que está en relación consigo mismo". Entonces, entendemos subjetividad como el modo en que nos pensamos y relacionamos con nosotros mismos en un determinado momento histórico y subjetivación como el proceso por el cual nos convertimos en sujetos es decir el proceso de constitución de nuestra subjetividad mediante prácticas históricas. Es preciso aclarar que dentro de un hombre hay muchos niveles de subjetivación, estos pueden ser consigo mismo o con el medio ambiente que le da vida. Al mismo tiempo, las formas de subjetivación son promovidas para rechazar el tipo de individualidad que se impuso siglos atrás y que, en ocasiones, aún encontramos en nuestras sociedades. Es decir el sujeto atado a una identidad o subjetividad identitaria: definida como la forma que toma la subjetividad en el pensamiento moderno: estable, interiorizada, individualizada, psicologizada (Morey, 1989).

2 Dirección, guión y montaje: Siddiq Barman. Afganistán, Japón e Irlanda. Año: 2003. Interpretación: Marina Golbahari (Niña/Osama), Khwaja Nader (Mulá), Arif Herati (Espandi), Zubaida Sahar (La madre), Hamida Refah (La abuela), Gol Rahman Ghorbandi (Talibán). Producción: Siddiq Barmak, Julia Fraser y Julie LeBrocquy. Música: Mohamed Reza Darwishi. Fotografía: Ebrahim Ghafuri. Dirección artística: Akbar Meshkini.
El espectáculo, omnipresente en nuestra cultura, implica la representación de la mujer desde las técnicas de la sexualidad como cuerpo-poder que a partir de esa representación controla, estabiliza y canoniza su papel social. Esas tecnologías, en una mirada foucaultiana, implican la producción de verdades, que son las verdades de las sociedades patriarcales. Así el nombre del padre es el único nombre propio, el nombre que legitima y otorga autoridad y poder, el logos que controla la producción de sentidos y determina la naturaleza y cualidad de las relaciones, el modus propio de la interacción humana.

De esa manera, se conforma la entidad identitaria: HOMBRE y su opuesto como NO HOMBRE, que es el lugar de la alteridad. Las mujeres al definirse por negatividad, ocupan el casillero de la otredad. Esa producción de identidades, naturaliza los arbitrarios y esencializa las identidades. Se marca sexualmente a los sujetos, al hacer coincidir al Hombre con los hombres, con los sujetos físicamente masculinos. De esa forma, la teoría crítica feminista ha puesto en cuestión la voluntad de universalidad y totalidad implícita en dicha concepción del sujeto (Colaizzi). No obstante, como ya señaló Foucault (1986), tranquiliza el pensar que el hombre es sólo una invención reciente y que, por tanto, desaparecerá en cuanto encuentre una forma nueva.

En ese sentido, se puede concluir que la Mujer es una construcción ficticia (de Lauretis, 1992) o un arbitrario cultural (Bourdieu, 1998), que ha servido para potenciar la dominación masculina.

Así las cosas se puede recordar con Simone de Beauvoir que "una no nace mujer", y por extensión con Donna Haraway que "uno no nace organismo". Los cuerpos, por tanto, son fabricados y producidos. El cine fabrica los cuerpos, las representaciones de mujeres y organismos femeninos, en esa canonización del ser llamado MUJER. En el hecho de ser mujer no existe nada que una naturalmente a las mujeres. "No existe incluso el estado de 'ser' mujer, que, en sí mismo, es una categoría enormemente compleja construida dentro de contestados discursos científico-sexuales y de otras prácticas sociales". Es así, que la conciencia de género, raza o clase es un logro forzado en nosotras por la terrible experiencia histórica de las realidades sociales contradictorias del patriarcado, del colonialismo y del capitalismo. "Las feministas de cyborg tienen que decir que nosotras no queremos más matriz natural de unidad y que ninguna construcción es total" (Haraway, 1995: 264 y 269).

A ellos hay que enfrentar a los cuerpos sin órganos, que -como se recordará- no se oponen a los cuerpos sino a los organismos. Son mezclas que rechazan las purezas porque los productos puros se han vuelto locos.

El saber/poder foucaultiano, quizás como en pocos discursos, se presenta produciendo a la mujer, como una construcción arbitraria (ficticia le llama de Lauretis), 
a partir de un destilado de discursos y prácticas diversas pero coherentes que dominan en las culturas occidentales (discursos críticos y científicos, literarios o jurídicos) y que funcionan a la vez como línea de fuga y como condición de existencia.

La Mujer, lo que no es hombre, es la conjugación de la Naturaleza y la Madre, la sede de la sexualidad y del deseo masculino, signo y objeto de intercambio social masculino. Es el término que designa a la vez las líneas de fuga de las ficciones que la cultura se cuenta a sí misma, como la condición de los discursos en los que están representadas esas ficciones.

En el cine, por su parte, se han potenciado esas relaciones arbitrarias y simbólicas que han sido establecidas culturalmente. Dichas relaciones sitúan a la mujer, al mismo tiempo, como objeto y fundamento de la representación, fin y origen del deseo del hombre y de su impulso de representarlo, y objeto y signo de (su) cultura y creatividad.

De la misma forma, el cine funciona como máquina de creación de imágenes, que al producir imágenes (de mujeres o no) tiende también a reproducir a la mujer como imagen. Hay que resaltar, en ese contexto, que -a diferencia de lo que se cree muy a menudo- no toda producción de subjetivación es liberadora por sí misma. Los casos abundan: Estados Unidos históricamente ha difundido por el cine sus valores capitalistas, patriarcales y racistas. El cine de westerns es, quizás, la muestra más clara. Citando otro ejemplo, en el caso de Irán, las reformas no han servido más que para explotar a las mujeres o para eliminarlas literalmente. Por ello, en El Círculo de Panahi ${ }^{3}$, al comenzar el film, se observa una especie de castigo divino con el nacimiento de una niña. Castigo que no hace más que ejecutarse durante todo el trayecto de las tres historias que desarrollan la trama. En ese sentido, la pregunta es ¿qué subjetivación produce esa forma de representación?

En el caso del cine, dicha subjetivación se define en relación (referente) a un sujeto masculino; con el hombre como único término de referencia. Alice, la protagonista del film de Woody Allen", no tiene más posibilidades que seguir los cánones establecidos de madre y esposa, teniendo como única opción -para poder liberarse y ser otra mujerromper con ellos radicalmente. Entonces, Alice cruza a través del espejo y no se deja intimidar por la voz del "amo". Deja de ser la chica bien educada que está dispuesta a asentir en todo con tal de mantener el diálogo y finalmente somos capaces de escuchar

3 Dirección, producción y montaje: Jafar Panahi. Irán / Italia. Año: 2000. Interpretación: Maryiam Palvin Almani (Arezou), Nargess Mamizadeh (Nargess), Fereshteh Sadr Orfani (Pari), Monir Arab (vendedor de tickets), Fatemeh Naghavi (madre), Elham Saboktakin (enfermera), Mojgan Faramarz (prostituta).Guión: Kambuzia Partovi. Fotografía: Bahram Badakshani. Dirección artística: Ira Raminfar. Dirección de producción: Abolfazl Laleh.

4 Director y guión: Woody Allen, EE.UU. Año: 1990. Interpretación: Joe Mantegna, Mia Farrow, William Hurt, , Dylan O'Sullivan Farrow, Matt Williamson, Julie Kavner, Billy Taylor, Keye Luke. Cinemat/Montador: Carlo DiPalma. Musica: Philip Braham y Douglas Furber. el "clash" de la caída El rompimiento es la decisión que ha tomado la paradigmática Alice $^{5}$.

En el cine, en el sentido de lo que venimos expresando, la mujer se encuentra ausente y cautiva. Ausente en cuanto sujeto teórico y cautiva porque su subjetivación se encuentra estancada, la historia no se moviliza. De esa forma, es preciso historizar multiplicar las micro-historias o arqueologías, en el sentido foucaultiano. Las emergencias históricas invitan a los sectores marginados, o que se encuentran en el afuera, a que relaten sus historias. En el cine tienen mucha fuerza las micro-historias o historias mínimas, porque ello implica no concebir a la mujer o al hombre como productos universales y transhistóricos, sino como devenires que nunca se estabilizan sino que se movilizan por las líneas de las historias que se van narrando.

Esto implica ubicar a las concreciones socioculturales en el interior de una red de prácticas interconectadas e interactuantes que funcionan en un específico punto en el tiempo y el espacio. Considerarlas como particulares productos temporales de las relaciones de poder entre superficies, cuerpos e instituciones (Colaizzi, 1990).

Si se analiza el campo de respuestas posibles para ensayar propuestas liberadoras que impliquen cambiar radicalmente lo que se ha venido dando como representación de las mujeres en el cine, hay que tener en cuenta que las salidas inspiradas en el psicoanálisis (como las de Teresa de Lauretis) o en la semiótica de tradición lingüística son problemáticas. Porque no todo se reduce al falo o a los sistemas cerrados de interpretación. Ni en el cine podemos reducir todo a los enunciados, significantes o sintagmas, sino que hay que aprovechar la fuerza liberadora del cine como arte y proceso de producción de subjetivaciones. "Siempre podemos relacionar el encuadre con la castración y el primer plano con el objeto parcial, pero no veo que eso pueda aportar algo al cine" (Deleuze, 1996: 97).

Como señalaba Antonin Artaud: “El cine llega precisamente en un momento de giro del pensamiento humano, en el momento preciso en el que el lenguaje usado pierde su

5 "Como Alicia y su ovillo de lana, hilo de una Ariadna sin heroicidades que el gato no cesa de enredar, el feminismo ha osado penetrar en el laberinto del lenguaje, ha soñado y ha sido soñado por el Rey Rojo, ha encontrado a su Humpty Dumpty y a su benévolo Caballero Rojo. También a nosotras nos han dicho que somos todas iguales y que deberíamos de "haber acabado a los siete años"; nosotras también hemos sido educadas, como nos habían enseñado, y hemos hecho cumplidos e intentado entablar conversación sólo para que nos dijeran que "no teníamos más cerebro que un mosquito"; nos hemos sentido confundidas también al ver que tomaban nuestras sencillas preguntas por acertijos, y hemos asentido a las respuestas que nos daban 'por no provocar una discusión'. Sabemos también que el lenguaje, sobre el que no tenemos ningún dominio, pues es verdad que está poblado de las intenciones de los otros, es, en el fondo, mucho más que un juego. Y lo mismo que Alicia consigue del estirado Humpty Dumpty que le explique el significado de la palabra Jabberwocky ('Usted parece muy hábil explicando palabras, señor' dijo Alicia. ¿Sería usted tan amable de decirme...'), me gusta imaginarme que el feminismo interroga ahora a la semiótica y a la teoría del cine, para pasar luego a la siguiente esquina, donde finalmente nos alcanzará el eco de la gran caída de Humpty Dumpty)" (de Lauretis, 1992: 11- 12)

Revista Internacional de Culturas y Literaturas, abril 2006 
poder de símbolo, en el que el espíritu está cansado del juego de las representaciones" (....) "Lo que es cierto es que a la mayor parte de las formas de representación se les ha pasado su momento".

Habría que ensayar propuestas para producir imágenes contra- hegemónicas, conocimientos heterogéneos y contradictorios. Concebir flexible y articuladamente la creación de imágenes.

No un cine de mujeres para mujeres, sino transgredir los códigos y las representaciones que históricamente se han construido para las mujeres desde el Sistema-Mundo-Moderno/Colonial-Blanco-Patriarcal. Hay que provocar, pervertir, convertir a la representación en una trampa de sí misma. Producir desde el afuera (antirepresentativo) otra subjetivación más flexible y cuestionadora de los códigos establecidos.

Se debe aprovechar la poderosa fuerza estética y política del cine para la liberación de género. Dispositivos, engranajes y máquinas nómadas que el cine patriarcal no pudo crear por sus discursos conservadores.

Cine como máquina experimentadora que permite conjugar, mezclar y articular diferentes estéticas, lenguajes y tendencias. Imágenes como espacios intermedios, construcciones performativas y políticas. Recuperar la corporeidad, pero no la que comienza y termina en la piel, sino el cuerpo-poder como liberación.

\section{REFERENCIAS BIBLIOGRÁFICAS}

Artaud, A., Cine, Madrid, Alianza, 2002.

Bourdieu, P., La distinción. Criterio y bases sociales del gusto, Madrid, Taurus. 1998.

Colaizzi, G. (ed), Feminismo y teoría del discurso, Madrid, Cátedra, 1990.

De Lauretis, T., Alicia ya no. Feminismo, semiótica, cine, Madrid, Cátedra, 1992.

Deleuze G., Conversaciones, Valencia, Pre-textos, 1996.

Foucault, M., Las palabras y las cosas, México, Siglo XXI, 1986.

Haraway, D., Ciencia cyborgs y mujeres. La reinvención de la naturaleza, Madrid, Cátedra, 1995.

Morey, M., “Introducción: La cuestión del método”, Tecnologías del yo, Barcelona, Paidós, 1989. 